DR. MANEL ISSAOUI (Orcid ID : 0000-0002-8866-0606)

DR. AMÉLIA MARTINS DELGADO (Orcid ID : 0000-0002-8996-1822)

Article type : Original Manuscript

\title{
Enrichment of white flour with spices positively impact safety and consumer acceptance of bread
}

\section{Running title: Quality bread from spices' enrichment}

\section{Manel Issaoui ${ }^{1,2}$, Nesrine Mahfoudhi' ${ }^{2,3}$, Guido Flamini ${ }^{4}$, Amélia Delgado ${ }^{5}$}

${ }^{1}$ Lab-NAFS 'Nutrition - Functional Food \& Vascular Health', Faculty of Medicine, University of Monastir, 5019 Monastir, Tunisia

${ }^{2}$ Departement of Biotechnology, Faculty of Science and Technology of Sidi Bouzid, University of Kairouan, 9100 Sidi Bouzid, Tunisia.

${ }^{3}$ Laboratory of Aromatic and Medicinal Plants, Centre of Biotechnology of Borj Cédria, BP 901 Hammamlif 2050, Tunisia

${ }^{4}$ Dipartimento di Farmacia, via Bonanno 6, 56126 Pisa, Italy

${ }^{5}$ MED- Mediterranean Institute for Agriculture, Environment and Development, University of Algarve Edf 8, Gambelas Campus 8005-191 Faro, Portugal

Corresponding author: amdelgado@ualg.pt

This article has been accepted for publication and undergone full peer review but has not been through the copyediting, typesetting, pagination and proofreading process, which may lead to differences between this version and the Version of Record. Please cite this article as doi: $\underline{10.1111 / \text { IJFS.14834 }}$

This article is protected by copyright. All rights reserved 


\section{Summary}

Aiming at increasing the nutritional value and sensory quality of bread, we assessed the enrichment of white flour with different levels of powdered cinnamon and pomegranate peel, through rheological, nutritional, aromatic, textural and sensory analyses. These extra ingredients were chosen for their richness in bioactive compounds and they differently affected bread quality. In relation to raw flour, introduced ingredients slightly decreased moisture and protein content, while increasing ash, fibre, and radical scavenging activity, which can be attributed to the sharing of aromatic compounds by cinnamon \& pomegranate peel during the bread making process. When cinnamon was incorporated at $1 \%$, the content of all furan derivatives was reduced up to $1 / 4$ of initial value, 2-pentyl furan totally disappeared, and furfuryl alcohol was reduced to $2.1 \%$. Despite enriched bread's texture was slightly worse, it was still acceptable in sensory tests, as 150 interviewed naive consumers preferred the new product over the control.

Keywords: enriched bread, nutritional value, safety, furan compounds, bioactive compounds, aroma, sensorial proprieties 


\section{Introduction}

Bread, most often baked from wheat flour, is a staple food and a symbol of food security, to the western countries and in particularly to the Mediterranean. Wheat was among the first crops to be domesticated by humans, and its cultivation, storage and processing dramatically evolved over time, especially during the 20th century, in consequence of the industrial revolution, which dramatically improved global food security. However, in the last decades, the mounting availability of ultra-processed foods is in the root of global obesity prevalence (WHO, 2020a,b). Ultra-processed foods can be defined as industrial products containing more than four ingredients, encompassing additives, hydrolysed proteins, modified starches, emulsifiers, hydrolysed and trans-fats and flavour enhancers. Such foods are generally dense in calories, nutritionally poor, and may contain health-deleterious compounds (Monteiro et al., 2018; Fardet, 2018). In the western societies, the evolution of wheat bread is illustrative of underlying societal, economic and technological changes, reflected in the food habits, as wheat bread evolved from a simple food (containing coarse flour, yeast, water and salt) into a complex bakery product. Such ultraprocessed "bread" (containing additives, simple sugars and fats) is made from white flours of low nutritional quality, notably in respect to fibres and polyphenols (Fardet, 2017). Due to the noted nutrition transition (WHO 2020a,b; Willet et al., 2019), the bread status downgraded from the omnipresence in every meal, to a frequent absence on the table, as can be easily observed worldwide, and confirmed by Food and Agriculture Organization of the United Nations' statistics (FAO, 2020). The partial replacement of bread by ultra-processed bakery products, in the context of deleterious dietary changes is a matter of concern and effective strategies urge to revert such trend (Inoue et al., 2018; Vandevijvere et al., 2019). One of them consists on promoting sustainable food systems based on regional agrobiodiversity, such as the Mediterranean Diet (Dernini \& Berry, 2015); another strategy is to fortify wheat flours (WHO, 2020b,c), a curative approach to combat identified short-term nutritional deficiencies, while educating for sustainable and healthy diets, in a long-term strategy. It has been claimed that food is much more than the sum of its components, encompassing several dimensions, including health and environment (Fardet \& Rock, 2015; FAO/WHO, 2019; Ruini et al., 2015). In this regard, many food industries are truly committed to provide healthier and more sustainable foods (e.g. Future Food Network), while others advertise recipes based in ethnical foods that include their industrial additives. Measures to improve food literacy among consumers are under implementation worldwide by governments and other organizations (Prescott et al., 2019; Truman et al., 2017; Willett et al., 2019) but confusion 
and misinformation still prevail among consumers. Several market trends can be perceived, one of which relates to the development of healthier, innovative products, which should desirably deliver well-recognised health-promoting compounds in a form easily absorbed by the organism, with sensorial features meeting consumers' expectations, good acceptance and should easily fit in the usual diet (Cardoso et al., 2019). Incremental innovation can be a win-win situation, allowing stepwise changes towards healthier and sustainable foods (Shih et al., 2018). Given that nutritional deficiencies are common to malnutrition and obesity, the enrichment of white flour may be a helpful short-term strategy to address both industrial, and consumers demands and a better understanding of bread as a complex food matrix will facilitate the way towards the agenda 2030 resolution. Recently several works have been published in this sense, as hazelnut-enriched bread that was shown to result in health-outcomes noticeable in the short-term (Devi et al., 2016). These authors claim such strategy to be effective in improving the diet, by increasing intakes of essential fatty acids, vitamins, polyphenols, fibres and other nutraceutical compounds. Similar results were reported by Skulas-Ray et al. (2011).

Klopsch et al. (2018) noted that isoflavones and other important phytonutrients from pulses (as pea, Pisum sativum, and lupin, Lupinus angustifolius) substantially resisted to breadmaking, with the exception of pigments (e.g. carotenoids and chlorophylls). Authors based their conclusions in comparing HPLC chromatograms from original plant material and bread, taking into account the enrichment proportions in wheat flour. In 2019, the same team reported identical achievements for Brassica sp. extracts as bread enriching ingredient (Klopsch et al., 2019). The success of such enriched bread formulations in promoting health has been confirmed by in vitro studies (GawlikDziki et al., 2014) as well as by clinical trials (Ferguson et al., 2019). In respect to fortified and enriched bread, works simultaneously covering health outcomes, technological aspects and consumer assessment, seem to be scarse.

Our work concerns the enrichment of wheat flour with natural ingredients containing healthpromoting compounds and we show the improvement of rheological, textural, nutritional, safety, aromatic and hedonic proprieties of bread through the incorporation of cinnamon or pomegranate at different levels.

\section{Materials and methods}

\subsection{Plant material, dough and bread preparation}


Cinnamon (Cinnamomum verum) powder and pomegranate peel (Punica granatum) powder were purchased from a local company, as well as all the other ingredients (flour, baker's yeast). Commercial Tunisian's white wheat flour labelled as "baking flour" was used. Cinnamon and pomegranate peel powder were incorporated in the dough at $0,0.25,0.5,0.75$ and $1 \% \mathrm{w} / \mathrm{w}$ level, in respect to wheat flour ( $1.5 \%$ for pomegranate peel powder only). A preliminary sensory analysis (both taste and texture) to adjust the formulation, lead to the elimination of 2 and $3 \%$ of cinnamon and pomegranate peel powder, judged as not acceptable, and maximum values were set to $1 \%$ for cinnamon and $1.5 \%$ for pomegranate peel in the trials to develop a product able to meet consumer's acceptance (Figure 1). White wheat bread formulated without substitute powder (0\%) was used as control. According to this protocol, ten samples were prepared: a control of white flour (UF), cinnamon-enriched flour (FFC) at 4 levels: $0.25 \%(\mathrm{Ca} 1), 0.5 \%(\mathrm{Ca} 2), 0.75 \%(\mathrm{Ca} 3)$, $1 \%(\mathrm{Ca} 4)$, and pomegranate-peel-enriched flour with (FFZ) at 5 levels: $0.25 \%(\mathrm{Zg} 1), 0.5 \%(\mathrm{Zg} 2)$, $0.75 \%(\mathrm{Zg} 3), 1.0 \%(\mathrm{Zg} 4)$ and $1.5 \%(\mathrm{Zg} 5)$. The main ingredients of the bread formulation were kept constant: flour (2 kg), salt (30 g), baker's yeast (40 g), improver (2 g) and water (1 L).

\subsection{Humidity, Hagberg Falling Number (HFN) and Flour water absorption (FWA)}

The humidity was determined by the reference method ISO 712: 2009, consisting in determining the water content of a $5 \mathrm{~g}$ bread sample kept for $1 \mathrm{~h} 30 \mathrm{~min}$ at $130{ }^{\circ} \mathrm{C}$, at atmospheric pressure . Hagberg Falling Number (HFN) was determined according to standard ISO 3093: 2009. Flour water absorption (FWA) was determined according to ISO 5530-1: 2013 using a Brabender Farinograph ${ }^{\circledR}$-E. A $300 \mathrm{~g}$ flour sample was weighed, placed in the Farinograph mixer, and water was added to form a dough. When the dough is formed, the Farinograph records the curve on a graph, which is shaped according to the amount of water added (absorption). The curve starts centred on a line of 500 Brabender units $[\mathrm{BU}] \pm 20 \mathrm{BU}$ and by adding water will go off this limit of $500 \mathrm{BU}$.

\subsection{Alveographic properties of dough}

Alveograph measurements were performed using the Alveo PC (Chopin Technology, La Garenne, France) following the standardized method (AACC 54-30). All the above mentioned enriched formulations were evaluated along with the control (wheat flour only). The alveographic parameters: tenacity (P), extensibility (L), baking strength (W) and elasticity (I.e) were automatically recorded by the software, during the four-step protocol. 1. a mixture of flour and salted water was prepared; 2 . five calibrated pieces of dough were prepared. 3 . Dough was let to 
rest for a moment. 4. every piece of dough automatically rises until the resulting bubbles burst, thus allowing measurements.

\subsection{Colour determination}

Colour parameters: lightness $\left(\mathrm{L}^{*}\right)$, redness $\left(\mathrm{a}^{*}\right)$ and yellowness $\left(\mathrm{b}^{*}\right)$ were measured with a colour flex spectrocolorimeter (Hunter Associates Laboratory Inc., Reston, VA). L* index indicates the lightness, in a 0-100 scale from dark to light, $\mathrm{a}^{*}$ value gives the degree of the green-red colour, and the $b^{*}$ value indicates the degree of the blue-yellow colour.

\subsection{Texture determination}

Six texture parameters: hardness, adhesiveness, cohesiveness, springiness, resilience and chewiness of bread were measured with a texturometer (Lloyd Instruments Ltd., West Sussex, UK) as previously described by Ayadi et al. (2009).

\subsection{Ash, fibre, total protein and gluten determination}

Determination of the ash rate was performed after incineration of the test sample at $900{ }^{\circ} \mathrm{C}$ according to ISO 2171:2007. From a 10g sample of flour, three gluten parameters were determined: wet gluten, dry gluten, and gluten index, according to ISO 21415-2:2015. Wet gluten was prepared from white flour or enriched flour with the Glutomatic 2200 gluten extractor (Perkin Elmer). The wet gluten was then dried at a minimum of $150{ }^{\circ} \mathrm{C}$ for 4 minutes in the Glutork 2020 apparatus, to determine the dry gluten. The Gluten Index is the amount of gluten that remains in the centrifuge sieve, relative to the total weight of the wet gluten. The total protein dosage of the samples was determined according to the Kjeldahl method. Dietary fibre's determination was carried out by the cellulose test.

\subsection{Antioxidant activity (DPPH test)}

The free-radical scavenging activity was determined by the classical method described by Blois (1958). The extraction step was performed with $0.1 \mathrm{~g}$ of sample and $2.9 \mathrm{ml}$ of ethanol. After centrifugation at $5000 \mathrm{rpm} / \mathrm{min}$ for $15 \mathrm{~min}$, the contents were filtered. The DPPH (di(phenyl)(2,4,6-trinitrophenyl)iminoazanium) solution was prepared by dissolving $2.5 \mathrm{mg}$ of DPPH in 100 $\mathrm{ml}$ of methanol. $50 \mu \mathrm{l}$ of sample extract or of standard (ascorbic acid) were added to $1.95 \mathrm{ml}$ of $\mathrm{DPPH}$, and kept in the dark for $45 \mathrm{~min}$, before measuring the absorbance at $515 \mathrm{~nm}$.

\subsection{Volatile compounds}

The odour/flavour profiles of the studied ingredients and corresponding bread formulations (raw white wheat flour, cinnamon powder, pomegranate peel powder, and breads) were analysed using a Supelco Solid Phase Micro Extraction (SPME) fibre coated with polydimethylsiloxane (PDMS, 
$100 \mu \mathrm{m}$ ); samples were placed into a $5 \mathrm{~mL}$ glass vial and left to equilibrate for $30 \mathrm{~min}$. Then the headspace was sampled for $50 \mathrm{~min}$ at room temperature using the same fibre and same conditions for all the samples and blanks, before each first SPME extraction and randomly repeated during each series. Quantitative comparisons of relative peak areas were performed between the same compounds in different samples. For GC-MS analysis, a Varian CP 3800 gas-chromatograph equipped with a DB-5 Capillary column (30 m x $0.25 \mathrm{~mm}, 0.25 \mu \mathrm{m}$ coating thickness) and a Varian Saturn 2000 ion trap mass detector were used. Injector and transfer line temperature were $250^{\circ} \mathrm{C}$ and $240^{\circ} \mathrm{C}$, respectively; working with a temperature program (from $60^{\circ} \mathrm{C}$ to $240^{\circ} \mathrm{C}$, at $3^{\circ} \mathrm{C}$ $\left.\min ^{-1}\right)$; carrier gas was He at $1 \mathrm{~mL} \mathrm{~min}^{-1}$; splitless injection. Compounds were identified on the basis of their retention times, in relation to those of pure standards, comparing their linear retention indices relative to the series of $n$-hydrocarbons, using the information from the National Institute of Standards and Technology library (NIST 2014 and ADAMS) and homemade library mass spectra, built from pure substances and components of known mixtures, in addition to MS literature data.

\subsection{Acceptance test}

Panellists involved in the study were previously interviewed to evaluate the overall liking (sensory discriminatory capabilities) of spices' enriched bread samples. Participants were selected from different regions of Tunisia using established screening criteria: i.e. level of education (high or incomplete), purchasing and consumption frequency, as well as familiarity with breads. Personal data and other relevant information for each selected panellist was recorded with their consent (age, gender, region of origin, socio-professional category, and consumption frequency of bread). Test participants were asked to evaluate, samples before and after the enrichment process, assessing their preference according to their degree of liking, by using a 9-point hedonic scale (like extremely: 9; like very much: 8; like moderately: 7; like slightly: 6; neither like nor dislike:

5; dislike slightly 4; dislike moderately: 3; dislike very much: 2; dislike extremely: 1) (Peryam \& Girardot, 1952). Bread samples (50 g) were served, at room temperature, in transparent glasses bottles, labelled with three digit code and presented to consumers after randomization, in blind conditions.

\subsection{Statistical analysis}

Data were processed by SPSS statistical package (Version 12.00 for Window, SPSS Inc. Chicago, Illinois, 2003). The significance of differences at a 5\% level among means was determined by 
ANOVA, using Tukey's test. For the acceptance sensory test, to check if a difference between samples existed, statistical analysis using the two-way ANOVA test was used.

\section{Results and Discussion}

\subsection{Rheological proprieties of dough from enriched flour (FF) compared with control (UF)}

Standard and regulations set the moisture content of flour for local consumption at 14\% (with a tolerance of $1 \%$ ). The moisture content of the wheat white flour used as control (UF) in this study was $13.67 \%$, thus complying with local regulations of $14 \pm 1 \%$. Falling number (FN) is an indicator of the amylase activity in the flour and consequently of the aptitude of the dough to fermentation. Analysis of the value of the fall time gives an idea of the quality of the activity of the flour amylase. Gélinas \& McKinnon (2006) suggest a fall time of 250 to 400 seconds, and the FN of the control (UF) is about 263s, which is in that range, meaning UF has a normal enzymatic activity. The incorporation of spices had no remarkable effect on the amylase activity (Table 1). The absorption test is one of the most used parameter in the bakery sector in estimating the amount of water that the dough will be able to absorb. The amount of added water determines the characteristics of dough and the gluten properties of flour by measuring the resistance opposed by the dough. The lower the amount of absorbed water, the harder the paste will be. Our control (UF) had a value of $53.70 \%$. The incorporation of cinnamon had no remarkable impact on flour water absorption (FWA), whereas a slight decrease of FWA was noticed when pomegranate peel powder was added (49.00\% for $\mathrm{Zg} 5$ vs. $53.70 \%$ for UF), which can be attributed to a probable lower water absorption capacity of the added ingredient $(\mathrm{Zg})$. To better understand and compare the rheological behaviour of the dough (made from UF and FF), we performed other tests with Alveograph Chopin apparatus. Table 1 shows the rheological proprieties (P, L, G, W, P/L and I.e) obtained from non-enriched and enriched wheat flour. Results show that rheological parameters of dough changed by the incorporation of spices. Pomegranate peel induced a remarkable modification of the rheological characteristics of dough, even at a small percentage. Hence, when the level of pomegranate peel increases, the tenacity of the dough (P) raised from $77 \mathrm{~mm} \mathrm{H}_{2} \mathrm{O}$ (UF) to $88 \mathrm{~mm} \mathrm{H}_{2} \mathrm{O}(0.25 \%$ of substitution level). At $1.5 \%$ of substitution level, pomegranate zest powder could double the value of tenacity $\left(166 \mathrm{~mm} \mathrm{H}_{2} \mathrm{O}\right)$. In parallel, with the increase of the tenacity value, a marked decrease in the value of the extensibility of this enriched flour (FFZ) was observed (35 mm at $1.5 \%$ of substitution level) when compared to UF control $(75 \mathrm{~mm})$. Such changes in tenacity and extensibility translate into a modification of the elastic resistance and 
extensibility balance of the dough, assessed by the parameter $\mathrm{P} / \mathrm{L}$. This ratio $\mathrm{P} / \mathrm{L}$ was about 1.03 for UF, reaching 4.75, with the increase of the substitution level. In the case of FFC dough (flour enriched with cinnamon), changes in tenacity and extensibility were not evident and consequently no modification on the P/L ratio occurred. Dough baking strength (W) of UF was about $204.0 \mathrm{x}$ $10^{-4} \mathrm{~J}$ and the incorporation of pomegranate peel (FFZ) caused an increase in the $\mathrm{W}$ of the dough until $260.0 \times 10^{-4} \mathrm{~J}$ (at 1.5\%). However, the $\mathrm{W}$ of the FFC dough decreased with the increase of enrichment $\left(168.0 \times 10^{-4} \mathrm{~J}\right.$ at $\left.1.0 \%\right)$. Elasticity (I.e) seems to be negatively affected by the presence of the spices. Our results are in agreement with those reported by many researchers and mainly attributed to the fibre provided by spices (Ayadi et al., 2009; Kim et al., 2012; Chahdoura et al., 2018). Several authors have reported changes in the rheological behaviour following the incorporation of ingredients in white flour (Wang et al., 2002; Borchani et al., 2011; Fakhfekh et al., 2017), which seem to mainly depend on the nature and concentration of these extra ingredients. Thus, some authors have noted an increase in the P/L ratio followed by a decrease in the baking strength (W) that they interpreted as poor hydration of the gluten due to a high retention capacity of the added ingredients and also to a fibre-gluten interaction affecting the structure of the gluten network. On the other hand, Chahdoura et al. (2018) demonstrated that baking strength rises with the fibre content and swilling decrease with the increase of polysaccharides given by cladodes powders. Same authors mentioned that tenacity and extensibility respond differently and are inversely proportional towards additives and $\mathrm{P} / \mathrm{L}$ ratio rises on the fortified flour (Wang et al., 2002; Borchani et al., 2011; Fakhfekh et al., 2017).

\subsection{Chromatic and textural proprieties of enriched and non-enriched breads}

The chromatic properties of a food are presented by the parameters $L^{*}, a^{*}$ and $b^{*}$. Our results show a value of 88.78 for UF, while we register lower lightness for cinnamon and pomegranate zest (55.73 and 72.51, respectively for FFC and FFZ). The low brightness of FFC is most probably due to its richness in ash (represented by minerals), fibres, pigments) and polyphenols (ANSESCIQUAL, 2020). Its incorporation in flour therefore decreased the luminosity of the obtained bread. FFZ also showed a remarkable effect on $b^{*}$ (yellow), and the addition of both spices generated a remarkable increase in the brown index ( $\mathrm{a}^{*}$ ), up to 0.36 for FFZ, and 0.86 in the case of FFC. Conversely, a slight increase of $\mathrm{a}^{*}$ was recorded in samples of FFZ. Figure1 shows enriched breads with crumbs stained toward darker colours of different shades, tending to brown and assuming a more vivid colour in comparison to white bread. As observed, the appearance of bread changed depending on both, the flour enrichment level and the used spice, with FFC 
corresponding to a more brownish bread, while FFZ led to more yellow bread. Changes in the appearance of bread upon enrichment and/or fortification have been demonstrated by several authors (Peng et al., 2010; Fakhfakh et al., 2017; Ning et al., 2017). Data about texture proprieties of UF (white flour) and enriched bread (FFC and FFZ) is presented in Table 2. Hardness, a commonly used indicator of bread quality, showed an increasing tendency with the enrichment level, increasing by nearly 4 fold for $1.0 \%$ respectively of FFC or FFZ. In fact, UF hardness was about $502 \mathrm{~g}$, but reached $2360 \mathrm{~g}$ at 1.0\% enrichment level (FFC or FFZ). Ning et al. (2017) obtained the same result when they added green tea powder, explaining this behaviour by the presence of cellulose that interlink forming a compact mesh structure and other authors claimed similar results by using fibre-rich ingredients. Fakhfekh et al. (2017) demonstrated that enriched bread with mallow powder showed an increased hardness that they explained by the interaction between the mallow fibres and the gluten, as according to them, the excess in fibre can alter the creation of a continuous gluten system. Similarly, Lim et al. (2011) worked on the effect of turmeric powder on bread hardness and reported an increase in hardness following the increase in enrichment level that they explain by the fact that incorporation of turmeric modifies the quantity of protein in the flour therefore affecting the uniform structure and firmness of the enriched bread. Fu et al. (2015) reported the increase in bread hardness by the addition of the lemon's fibre, and posed three hypothesis, all related to the nature of fibre: the rigidity of the lemon's fibre, the competition between lemon fibre and flour compounds for water, and/or because the insoluble dietary fibre of lemon may interfere with the formation of gluten network. A certain dilution effect of gluten with the enrichment should be considered as a probable cause for the observed lower gluten level. In our study we have noticed that cinnamon (produce a harder bread $(2364 \mathrm{~g}$ at 1\% FFC) than that obtained with pomegranate (1871 $\mathrm{g}$ at $1 \% \mathrm{FFZ})$; these differences in terms of hardness may be due to the large differences in fibre content between the two extra ingredients (ANSES-CIQUAL, 2020). We registered identical behaviour for adhesiveness, while cohesiveness decreased by increasing the level of enriching ingredients. Our results are thus comparable to those of some studies on bread produced with wheat flour added of fibre-rich ingredients (Lim et al., 2011; Fu et al., 2015; Fakhfekh et al., 2017).

\subsection{Nutritional proprieties and free radical scavenging activities of enriched and non- enriched flour}

In the present study we chose to enrich white flour with two spices frequently used in Mediterranean diet: cinnamon and pomegranate peel. The incorporation of spices led to an 
increase in the ash content in both FFC (0.64\% for $\mathrm{Ca} 4)$ and FFZ (0.65\% for $\mathrm{Zg} 5)$ in comparison to UF $(0.56 \%)$. Increased ash content means a probable increase in microelements in the enriched bread similarly to fortified bread, in respect to health benefits of conveyed minerals and their importance on a balanced diet (Assunção et al., 2007; Cardoso et al., 2019). Based on the study carried out by Akhtar et al. (2008), iron may also contribute to extend the shelf life of enriched flour by inhibiting mould contamination. In the present work, the control (UF) had less than 0.3 $\mathrm{g} / 100 \mathrm{~g}$ dietary fibre that increased up to 3 fold $(0.83 \mathrm{~g} / 100 \mathrm{~g})$ for cinnamon enrichment (Ca4, Table 3). According to ANSES-CIQUAL (2020), the estimated value for cinnamon dietary fibres' content is $53.1 \mathrm{~g} / 100 \mathrm{~g}$, more than half the weight of cinnamon powder, which may explain the increase of fibre content of FFC. In contrast, FFZ has not shown a so significant increase in fibre, since pomegranate zest does not naturally have a so higher content $(2.3 \mathrm{~g} / 100 \mathrm{~g}$ based on ANSESCIQUAL, 2020). Thus, the consumption of cinnamon-enriched bread may provide a relevant fibre supplementation to the diet, if recalling that in the European Union the fibres' Dietary Reference Value for normal adults is about $25 \mathrm{~g} /$ day (EFSA, 2019). It is also noteworthy that Erukainure et al. (2013) refer that fibre's enriched cake could be useful against haematological and biochemical changes associated with diabetes mellitus. The protein content of UF is $10.80 \mathrm{~g} / 100 \mathrm{~g}$, and we noticed a slight decrease with enrichment level (Table 3) for both FFC (10.70 g/100g for Ca4) and FFZ (10.60 g/100g for Zg5), which was accompanied by a decrease of total gluten, probably because part of the white flour is replaced by the enriching ingredient, but not in every gluten indicator. Gluten is a generic term for the proteins typical of certain cereals, accounting for the protein fraction insoluble in water from the protein complex of wheat grains. The composition of this fraction is essential for the industrial quality of bakery products, since it can confer viscoelastic properties such as water absorption capacity, cohesion, viscosity and elasticity of the dough (Oikonomou et al., 2015). During our study, we determined three gluten indicators: gluten index (expressed as \%), dry gluten (in g) and wet gluten (in g). The wet gluten in UF was about $10.38 \mathrm{~g} / 100 \mathrm{~g}$, and the enriching process seems to decrease the amount of wet gluten in flour. Hence, a marked decrease was noticed for FFZ (6.17 g for Zg5). Wet gluten seems to vary inversely to flour enrichment level as we also observed the decrease in wet gluten upon cinnamon addition, although less pronounced (Table 3). The gluten index (GI) is a fast way to measure wheat quality and an indicator for predicting whether the quality of the gluten is low (GI $<30 \%$ ), normal (GI $=30-80 \%$ ) or strong (GI> 80\%) (Oikonomou et al., 2015). In our case, all the values of GI are higher than $95 \%$, and up to $99.8 \%$ for $\mathrm{Zg} 5$ (pomegranate peel), so we may classify all 
our enriched bread samples at least in the normal category or, more likely, in the strong one. Table 3 shows the effects of addition of spices on the antioxidant activity (DPPH assay) of enriched bread. Our results show significantly higher $(\mathrm{p} \leq 0.05)$ values for antioxidant activity in the enriched samples (FFC and FFZ) than in the control. Hence, the radical scavenging activity increased when increasing the spices enrichment level, as can be observed in Table 3. Furthermore, the anti-oxidant activity of FFC samples (cinnamon) was higher than FFZ (pomegranate peel) in scavenging the DPPH radical, which can be explained by the different richness of these ingredients in antioxidant compounds, although both bringing benefits when compared to the control UF (white flour). In fact, spices exhibit higher oxygen radical absorption activity (ORAC) and are potent sources of antioxidant compounds mainly polyphenols (SkulasRay et al., 2011). Gawlik-Dziki et al. (2015) have demonstrated that antioxidant potential of enriched bread was positively correlated to the amount of quinoa leaf added. Fakhfekh et al. (2017) also claimed that adding mallow powder to white flour increased the level of flavonoids and consequently of the antioxidant capacity of the enriched bread.

\subsection{Odour compounds of white wheat flour (UF) and of enriched flour (FF)}

The quality of bread depends on its composition in aromatic compounds and other molecules contributing to the odour, which we studied in wheat flour, cinnamon and pomegranate zest powder (Table 4). We have detected 13 aromatic compounds, from different chemical classes in the raw wheat flour (UF) (data not shown): $n$-heptane (14.7\%), 3-ethyl-1-hexanol (18.9\%), limonene (19.4\%), isocetane (13.0\%), isobutyric acid (8.3\%), hexanal (4.1\%), isopentyl alcohol (3.1\%), 1,8-cineole (7.8\%), nonanal (3.8\%), n-dodecane (1.0\%) and decanal (1.1\%). Chai et al. (2019) detected thirty-nine volatile compounds in raw flour, covering seven groups dominated by aldehydes with the predominance of hexanal. In the present work we found acetic acid (47.7\%), limonene (17.9\%), 1-butanol (4.6\%), benzyl alcohol (3.0\%), linalool (3.1\%), nonanal (3.0\%) and hexanal $(2.1 \%)$ as the principal aromatic compounds of the studied pomegranate peel powder (Table 4), while(E)-cinnamaldehyde, carvone, $\alpha$-copaene, linalool, $\delta$-cadinene and $\alpha$-muurolene were the main volatile compounds found in cinnamon samples (Table 4). (E)-cinnamaldehyde is known to contribute to the typical fragrance of cinnamon (Rao \& Gan, 2014; Friedman, Nobuyuki \& Harden, 2000), and is also effective against several human pathogens, such as Salmonella sp., Escherichia coli, etc. (Friedman, Nobuyuki \& Harden, 2000). However, (E)-cinnamaldehyde is not very stable to heating, and may decompose into benzaldehyde, contrarily to other cinnamon compounds such as eugenol, linalool and carvone (Friedman, Nobuyuki \& Harden, 2000). When 
baking bread, we assist to the formation of certain compounds, among which those belonging to the furan family: dihydro-2-methyl-3(2H)-furanone, furfural, furfuryl alcohol, 5-methylfurfural, 2pentyl furan, which have been recognized as chemical contaminants (EFSA, 2011, 2017; FDA, 2004; FAO/WHO, 2011) and their precursors are unsaturated fatty acids, carbohydrates, amino acids, vitamin C and carotenoids (EFSA, 2017). Heat treatment (e.g. cooking, baking) stimulates the genesis of these compounds in a wide range of foods products, including cookies, breakfast cereals, and bread (FAO/WHO, 2011). In this study, bread enrichment was found to have a protective effect against the accumulation of such compounds. Indeed, the addition of 1\% cinnamon was able to mitigate the content of furan derivatives up to $1 / 4$ of the initial content and, in the case of 2-pentyl furan, cinnamon was able to completely make it disappear from the finished product and furfuryl alcohol was reduced to $2.1 \%$, when $1 \%$ of cinnamon was added (Table 4 ). An acceptable daily intake (ADI) of $0-0.5 \mathrm{mg} / \mathrm{kg}$ bodyweight for furfuryl alcohol has been set by the Joint FAO/WHO Expert Committee on Food Additives (JECFA) (FAO/WHO, 2000; Okaru \& Lachenmeier, 2017). In terms of series, furan compounds were present at $18.3 \%$ when $0.25 \%$ cinnamon was added, but for an addition of $1 \%$ these compounds dropped to $4.8 \%$. This trend was not detected for the enrichment with pomegranate zest (FFZ) (11.8 vs. 14.0\%, respectively for Zg1 vs. Zg5). According to the European Food Safety Authority, EFSA, the baking time and the degree of browning are part of the rise in furan content in toast. While taking into account the high volatility of furan, certain cooking practices can help reduce dietary exposure to furan and methyl furans (furan b.p. $32^{\circ} \mathrm{C}$ ) (EFSA, 2017; Kettlitz et al., 2019). In addition to furan compounds, pyrazine derivatives were detected among the newly formed compounds following the cooking process. In the present work, we monitored four pyrazine derivatives: methyl pyrazine, 2,6dimethylpyrazine, 2-ethylpyrazine, 2,3-dimethylpyrazine (Table 4), and we observed that methyl pyrazine decreased with the enrichment level of cinnamon (from $1.4 \%$ UF to $0.3 \% \mathrm{FFC}$, respectively for $\mathrm{Ca} 0.25$ and $\mathrm{Ca} 1 \%$ ). Again, the content of this compound was not affected by the enrichment with pomegranate zest (Table 4). Regarding 2,3-dimethylpyrazine, it was reduced to $0.2 \%$ in bread enriched with $1 \%$ of cinnamon. In general, cinnamon was able to mitigate the appearance of some aromatic compounds, particularly at $1 \%$, whereas pomegranate zest did not seem to have an effect. Pyrazines belong to a class of heterocyclic compounds with two nitrogen atoms in the para position (EFSA, 2008). They have an impact on the taste of foods, playing a major role in the "roasted" flavour. Recently, pyrazines are included in the list of flavourings authorized by the European Union and are incorporated by the food industry to imitate certain 
natural flavours (EFSA, 2008) and are positively correlated with browning polymers (Yu et al., 2017). Isopentyl alcohol was detected in a high percentage in all bread samples (more than $26 \%$ in $\mathrm{Zg} 0.25 \%$ ). Based on FoodDB (2020), isopentyl alcohol is a by-product of gut microbial fermentation and it is an authorised flavouring agent. 2-Methyl butan-1-ol is present at a considerable level in all samples (Table 4). All the bread samples contained acetoin (or as3hydroxy-2-butanone) to varying degrees (3.7 to 7.5\%), (Table 4) resulting from a fermentation process, as detailed by Bratovanova (1997). Acetoin which is granted with Generally Recognized As Safe or GRAS status has a reminiscent odour of creamy yogurt and a taste of fat butter (Xiao \& $\mathrm{Lu}, 2014)$.

\subsection{Hedonic study and acceptance test of enriched bread}

In the field of new food development, the use of sensory analyses is essential to demonstrate above all the acceptability of foods by consumers. We studied the impact of white flour enrichment on the degree of consumer's appreciation of spices' enriched bread compared to white bread (Fig 2). One hundred and fifty consumers participated in this study. Enriched bread samples registered an overall liking from 6.80 to 7.52 and were hence more appreciated than white bread (overall liking of about 5.13). On other terms, consumers seem to be indifferent to white bread, while they appreciate the enriched formulations. Only 30\% of total consumers preferred white bread, whereas more than $78 \%$ appreciated the Cal bread (with cinnamon), and $74 \%$ the $\mathrm{Zg} 2$ (with pomegranate zest). The results of the sensory evaluation of enriched bread formulations, as well as of the control sample (UF) were subjected to statistical analysis using the two-way ANOVA test (Table 5). The results show a clear significant effect of age on the overall appreciation of the FFZ bread $(\mathrm{P}<0.001)$. However, we found no significant effect of the gender or of the interaction between the two tested factors. In the case of FFC bread, the statistical results revealed significant effects of the gender and the interaction between gender and age $(\mathrm{P}<0.01)$ and for the control sample, both, the gender and the age had significant effect on the global appreciation $(\mathrm{P}<0.01)$ (Table 5). Sensory analysis was carried out also by testing texture, odour and taste for both enriched (FFC and FFZ) and white breads (UF). The taste of Zg2 seems to be the preferred one (score 7.79), while the texture of $\mathrm{Zg} 1$ was the most appreciated; followed by $\mathrm{Zg}$ 2. Ca1 had the best odour, based on feedback by consumers. We have noticed that the degree of appreciation of FFC decreased with the increase of cinnamon concentration in the formulation.

\section{Concluding remarks}


In the present work, the investigation of the effects of the incorporation of two spices, cinnamon and pomegranate peel powder, into white flour at different levels on the rheological, nutritional, aromatic and sensory characteristics of prepared bread were studied. Firstly, cinnamon and pomegranate peel powder are rich in bioactive compounds, such as dietary fibre, aromas and antioxidant compounds. Interactions between compounds increase the matrix effect changing rheological properties and enhancing the nutritive value of enriched bread. Cinnamon seems to be able to slow down and even inhibit the formation of certain furan compounds considered carcinogenic by the authorities, therefore contributing to increased food safety. However, texture and sensorial proprieties of the new developed bread may be negatively influenced, as demonstrated by the incorporation of high levels of spices. Finally, besides the right amount of added ingredients, it is also necessary to properly choose the processing parameters, in order to obtain healthy bakery products with a high level of antioxidants and micronutrients, minimising the negative effects on rheological properties of the dough, and promoting the desirable sensory characteristics of bread.

\section{Acknowledgments}

This research was supported by the Tunisian Ministry of Higher Education and Scientific Research (UR03ES08). Aroma analyses were performed at the Dipartimento di Farmacia, Università di Pisa, Italy. Other work was carried at the Department of Biotechnology, Faculty of Science and Technology of Sidi Bouzid, University of Kairouan, Sidi Bouzid, Tunisia. We would like to thank Ing. Souhail Besbes.

\section{Author statements on conflict of interest, ethics and data availability}

The authors declare that there are no conflicts of interests, personal data protection and confidentiality was ensured, and no ethics approval were required for this research. Research data are not shared.

\section{References}

A.A.C.C. Approved Methods of Analysis, 11th Edition - AACC Method 54-30.02. Alveograph Method for Soft and Hard Wheat Flour

Akhtar, S., Anjum, F.M., Rehman, S.U., Sheikh, M.A. \& Farzana, K. (2008). Effect of fortification on physico-chemical and microbiological stability of whole wheat flour. Food Chemistry, 110, 113-119. 
ANSES/CIQUAL (2020). version 2020 of the ANSES-CIQUAL food composition table. URL: https://ciqual.anses.fr/\#/cms/2020-anses-ciqual-table/node/19 . Accessed 01/06/2020.

Assunção, M.C.F., Santos, I.S., Barros, A.J.D., Gigante, D.P. \& Victora, C.G. (2007). Effect of iron fortification of flour on anemia in preschool children in Pelotas, Brazil. Revista de Saúde Pública, 41, 539-548.

Ayadi, M.A., Abdelmaksoud, W., Ennouri, M. \& Attia, H. (2009). Cladodes from Opuntia ficus indica as a source of dietary fiber: effect on dough characteristics and cake making. Industrial Crop Product, 30, 40-47.

Blois, M.S. (1958). Antioxidant determinations by the use of a stable free radical. Nature, 181, 1199-1200.

Bratovanova, P. (1997). Diacetyl, Acetoin and Acetaldehyde in the Flavour of Doughy PartManufactured Goods and Bread, Prepared with Leavens of Lactococci and Lactobacilli, Biotechnology \& Biotechnological Equipment, 11, 53-59.

Borchani, C., Masmoudi, M., Besbes, S., Attia, H., Deroanne, C. \& Blecker, C. (2011). Effect of date flesh fiber concentrate addition on dough performance and bread quality. Journal of Texture Studies, 42, 300-308.

Cardoso, R.V.C., Fernandes, Â., Gonzaléz-Paramás, A.M., Barros, L. \& Ferreira, I.C.F.R. (2019). Flour fortification for nutritional and health improvement: A review. Food Research International, 125, 108576. doi:10.1016/j.foodres.2019.108576

Chai, D., Li, C., Zhang, X., Yang, J., Liu, L., Xu, X., Du, M., Wang, Y., Chen, Y \& Dong, L. (2019). Analysis of Volatile Compounds from Wheat Flour in the Heating Process. International Journal of Food Engineering, 20190252. doi: 10.1515/ijfe-2019-0252

Chahdoura, H., Chaouch, M.A., Chouchéne, W., Chahed, A., Achour, S., Adouni, K., Mosbah, H., Majdoub, H., Flamini, G. \& Achour, L. (2018). Incorporation of Opuntia macrorhiza Engelm. in cake-making: Physical and sensory characteristics. LWT-Food Science and Technology, 90, $15-21$.

This article describes the impact of the incorporation of Opuntia macrorhiza Engelm. in white flour on the physical and sensorial characteristics of cake-making products, and it is important in the sense that it highlights the relevance of the use plant extracts to enhance the nutritional value of pastry product. 
Devi, A., Chisholm, A., Gray, A., Tey, S.L., Williamson-Poutama, D., Cameron, S.L. \& Brown, R.C. (2016). Nut-enriched bread is an effective and acceptable vehicle to improve regular nut consumption. European Journal of Nutrition, 55, 2281-2293.

Dernini, S. \& Berry, E.M. (2015). Mediterranean Diet: From a Healthy Diet to a Sustainable Dietary Pattern. Frontiers in Nutrition, 2, 15.

EFSA (2008). Scientific Opinion of the Panel on Food Additives, Flavourings, Processing Aids and Materials in Contact with Food on a request from Commission on FGE.17, Rev1: Pyrazine derivatives from chemical group 24. The EFSA Journal, 812, 1-59.

Erukainure, O.L., Ebuehi, O.A.T., Adeboyejo, F.O., Aliyu, M. \& Elemo, G.N. (2013). Hematological and biochemical changes in diabetic rats fed with fiber-enriched cake. Journal of Acute Medicine, 3, 39-44.

Fakhfakh, N., Jdir, H., Jridi, M., Rateb, M., Belbahri, L., Ayadi, M.A., Nasri, M. \& Zouari, N. (2017). The mallow, Malva aegyptiaca L. (Malvaceae): Phytochemistry analysis and effects on wheat dough performance and bread quality. LWT-Food Science and technology, 75, 656-662.

This article establishes a correlation between the flour's incorporation level of the mallow powder and bread quality. We consider it essential for our investigation for being a reference work reporting the importance of the enrichment process in improving nutritional and sensorial proprieties of resulting bread.

Fardet, A. (2017). Do the Physical Structure and Physicochemical Characteristics of Dietary Fibers Influence their Health Effects? In: Dietary Fibre Functionality in Food \& Nutraceuticals: From Plant to Gut (edited by F. Hosseinian, B. D. Oomah \& R. CamposVega). Hoboken, NJ, USA: John Wiley \& Sons, Inc.

Fardet, A. (2018). Characterization of the Degree of Food Processing in Relation With Its Health Potential and Effects. Advances in Food and Nutrition Research, 85: 79-129.

This article is a reference article that classifies foods according to their degree of processing and it is also essential for our investigation, since it reviews the association between the degree of food processing and the chronic disease risk prevalence and explores the impact of technological processes on food health potential, considering both matrix and compositional effects.

Fardet, A. \& Rock, E. (2015). From a Reductionist to a Holistic Approach in Preventive Nutrition to Define New and More Ethical Paradigms. Healthcare, 3, 1054-1063. 
FAO /WHO. (2000). Evaluations of the Joint FAO/WHO Expert Committee on Food Additives (JECFA). Furfuryl Alcohol. URL: https://apps.who.int/food-additives-contaminants-jecfadatabase/chemical.aspx?chemID=2772 . Accessed 15/08/2020.

FAO/WHO (2011). Commission du Codex Alimentarius. Programme Mixte FAO/OMS sur les Normes Alimentaires, Comité du CODEX sur les Contaminants dans L'Alimentation, (5ème Session, CX/CF 11/5/13, document de travail sur le furane). La Haye, les Pays-Bas

FAO and WHO. (2019). Sustainable healthy diets - Guiding principles. Rome.

FAO (2020). FAO Cereal Supply and Demand Brief. URL: http://www.fao.org/worldfoodsituation/csdb/en/. Accessed 10/08/2020.

Ferguson, J., Wolska, A., Remaley, A.T., Stojanovski, E., MacDonald-Wicks, L., \& Garg, M.L., (2019). Bread enriched with phytosterols with or without curcumin modulates lipoprotein profiles in hypercholesterolaemic individuals. A randomised controlled trial. Food \& Function, 10, 2515-2527.

FoodDB (2020). FooDB Version 1.0. URL: www.foodb.ca. Accessed 12/08/2020.

Friedman M., Nobuyuki, K. \& Harden, L.A. (2000). Cinnamaldehyde Content in Foods Determined by Gas Chromatography-Mass Spectrometry. Journal of Agricultural and Food Chemistry, 48, 5702-5709.

Fu, J.T., Chang, Y.H. \& Shiau, S.Y. (2015). Rheological, antioxidative and sensory properties of dough and Mantou (steamed bread) enriched with lemon fiber. LWT - Food Science and Technology, 61, 56-62.

Gawlik-Dziki, U., Dziki, D., Swieca, M., Seczyk, Ł., Rozyło, R. \& Szymanowska, U. (2015). Bread enriched with Chenopodium quinoa leaves powder - The procedures for assessing the fortification efficiency. LWT - Food Science and Technology, 62, 1226-1234.

Gawlik-Dziki, U., Świeca, M., Dziki, D., Sęczyk, Ł., Złotek, U., Różyło, R., Kaszuba, K., Ryszawy, D., \& Czyż, J. (2014). Anticancer and antioxidant activity of bread enriched with broccoli sprouts. BioMed Research International, 608053. https://doi.org/10.1155/2014/608053

Gelinas, P. \& McKinnon, C.M. (2006). Effect of wheat variety, farming site, and bread-baking on total phenolics. International Journal of Food Science and Technology, 41, 329-332.

Inoue, Y., Qin, B., Poti, J., Sokol, R. \& Gordon-Larsen, P. (2018). Epidemiology of Obesity in Adults: Latest Trends. Current obesity reports, 7, 276-288.

ISO 712: 2009. Cereals and cereal products - Determination of water content - reference method. 
ISO 3093:2009. Soft wheat, rye and their flours, durum wheat and their semolina - Determination of the fall index according to Hagberg-Perten.

ISO 5530-1: 2013. Wheat flour — Physical characteristics of doughs — Part 1: Determination of water absorption and rheological properties using a farinograph.

ISO 2171:2007. Cereals, pulses and by-products — Determination of ash yield by incineration.

ISO 21415-2:2015. Wheat and wheat flour — Gluten content - Part 2: Determination of wet gluten and gluten index by mechanical means.

Kettlitz, B., Scholz, G., Theurillat, V., Cselovszky, J., Buck, N.R, O’ Hagan, S., Mavromichali, E., Ahrens, K., Kraehenbuehl, K., Scozzi, G., Weck, M., Vinci C., Sobieraj, M. \& Stadler, R.H. (2019). Furan and Methylfurans in Foods: An Update on Occurrence, Mitigation, and Risk Assessment. Comprehensive Reviews in Food Science and Food Safety, 18, 738-752.

Kim, J.H., Lee, H.J., Lee, H.S., Lim, E.J., Imm, J.Y. \& Suh, H.J. (2012). Physical and sensory characteristics of fibre-enriched sponge cakes made with Opuntia humifusa. LWT - Food Science and Technology, 47, 478-484.

Klopsch, R., Baldermann, S., Voss, A., Rohn, S., Schreiner, M., \& Neugart, S. (2018). Bread Enriched with Legume Microgreens and Leaves-Ontogenetic and Baking-Driven Changes in the Profile of Secondary Plant Metabolites. Frontiers in Chemistry, 6, 322.

Klopsch, R., Baldermann, S., Hanschen, F.S., Voss, A., Rohn, S., Schreiner, M., \& Neugart, S. (2019). Brassica-enriched wheat bread: Unraveling the impact of ontogeny and breadmaking on bioactive secondary plant metabolites of pak choi and kale. Food Chemistry, 295, 412-422.

Lim, H.S., Park, S.H., Ghafoor, K., Hwang, S.Y. \& Park, J. (2011). Quality and antioxidant properties of bread containing turmeric (Curcuma longa L.) cultivated in South Korea. Food Chemistry, 124, 1577-1582.

Monteiro, C.A., Cannon, G., Moubarac, J.C., Levy, R.B., Louzada, M.L.C., Jaime, P.C. (2018). The UN Decade of Nutrition, the NOVA food classification and the trouble with ultraprocessing. Public Health Nutrition, 21, 5-17.

Ning, J., Hou, G.G., Sun, J., Wan, X., \& Dubat, A. (2017). Effect of green tea powder on the quality attributes and antioxidant activity of whole-wheat flour pan bread. LWT - Food Science and Technology, 79, 342-348.

Okaru, A.O \& Lachenmeier, D.W. (2017). The Food and Beverage Occurrence of Furfuryl Alcohol and Myrcene Two Emerging Potential Human Carcinogens? Toxics, 5, 9. 
Oikonomou, N.A., Bakalis, S., Rahman, M.S. \& Krokida, M.K. (2015). Gluten Index for Wheat Products: Main Variables in Affecting the Value and Nonlinear Regression Model. International Journal of Food Properties, 18, 1-11.

Peng, X., Ma, J., Cheng, K.W., Jiang, Y., Chen, F. \& Wang, M. (2010). The effects of grape seed extract fortification on the antioxidant activity and quality attributes of bread. Food Chemistry, 119, 49-53.

Prescott, M.P., Burg, X., Metcalfe, J.J., Lipka, A.E., Herritt, C. \& Cunningham-Sabo, L. (2019). Healthy Planet, Healthy Youth: A Food Systems Education and Promotion Intervention to Improve Adolescent Diet Quality and Reduce Food Waste. Nutrients, 11, 1869. pii: E1869. doi: 10.3390/nu11081869

Peryam D.R. \& Girardot N.F. (1952). Advanced taste test method. Food Engineering, 24, 58-61.

Rao, P.V. \& Gan, S.H. (2014). Cinnamon: A Multifaceted Medicinal Plant. Evid Based Complement Alternat Med, 2014, 1-12 642942. doi: 10.1155/2014/642942

Ruini, L.F., Ciati, R., Pratesi, C.A., Marino, M., Principato,. L. \& Vannuzzi E. (2015). Working toward Healthy and Sustainable Diets: The "Double Pyramid Model" Developed by the Barilla Center for Food and Nutrition to Raise Awareness about the Environmental and Nutritional Impact of Foods. Frontiers in Nutrition, 4, 9. doi: 10.3389/fnut.2015.00009

Shih, D.H., Lu, C.M., Lee, C.H., Cai, S.Y., Wu, K.J., Tseng, M.L. (2018). Eco-Innovation in Circular Agri-Business. Sustainability, 10, 1140.

Skulas-Ray, A.C., Kris-Etherton, P.M., Teeter, D.L., Chen, C.Y.O., Vanden Heuvel, J.P. \& West, S.G. (2011). A High Antioxidant Spice Blend Attenuates Postprandial Insulin and Triglyceride Responses and Increases Some Plasma Measures of Antioxidant Activity in Healthy, Overweight Men. The Journal of Nutrition, 141, 1451-1457.

Vandevijvere, S., De Ridder, K., Fiolet, T., Bel, S. \& Tafforeau J. (2018). Consumption of ultraprocessed food products and diet quality among children, adolescents and adults in Belgium. European Journal of Public Health, 58, 3267-3278.

Truman, E., Lane, D., \& Elliott, C. (2017). Defining food literacy: A scoping review. Appetite, 116, 365-371.

Wang, J., Rosell, C.M., Benedito. \& de Barber, C. (2002). Effect of the addition of different fibers on wheat dough performance and bread quality. Food Chemistry, 79, 221-226.

Willett, W., Rockström, J., Loken, B., Springmann, M., Lang, T., Vermeulen, S., Garnett, T., Tilman, D., DeClerck, F., Wood, A., Jonell, M., Clark, M., Gordon, L. J., Fanzo, J., Hawkes, 
C., Zurayk, R., Rivera, J.A., De Vries, W., Majele-Sibanda, L., Afshin, A., ... Murray, C. (2019). Food in the Anthropocene: the EAT-Lancet Commission on healthy diets from sustainable food systems. Lancet, 393, 447-492.

World Health Organization, WHO (2020a). Obesity and overweight. URL: https://www.who.int/en/news-room/fact-sheets/detail/obesity-and-overweight. Accessed 10/5/2020.

World Health Organization, WHO (2020b). Double burden of malnutrition. URL: https://www.who.int/nutrition/double-burden-malnutrition/en/. Accessed 11/8/2020.

World Health Organization, WHO (2020c) WHO/FFI joint harmonization workshop for wheat and flour fortification. URL: http://www.emro.who.int/nutrition/nutrition-events/fortificationworkshop-jordan.html. Accessed 23/06/2020.

Xiao, Z. \& Lu, J.R. (2014). Generation of Acetoin and Its Derivatives in Foods. Journal of Agricultural and Food Chemistry, 62, 6487-6497.

Yu, A.N., Zhou, Y.Y. \& Yang, Y.N. (2017). Kinetics of browning and correlations between browning degree and pyrazine compounds in 1-ascorbic acid/acidic amino acid model systems. Food Chemistry, 221, 1678-1684. 
Table 1. Humidity and rheological proprieties of wheat flour (UF) and samples of enriched flour with cinnamon $(\mathrm{Ca})$ and pomegranate peel $(\mathrm{Zg})$ with different percentages

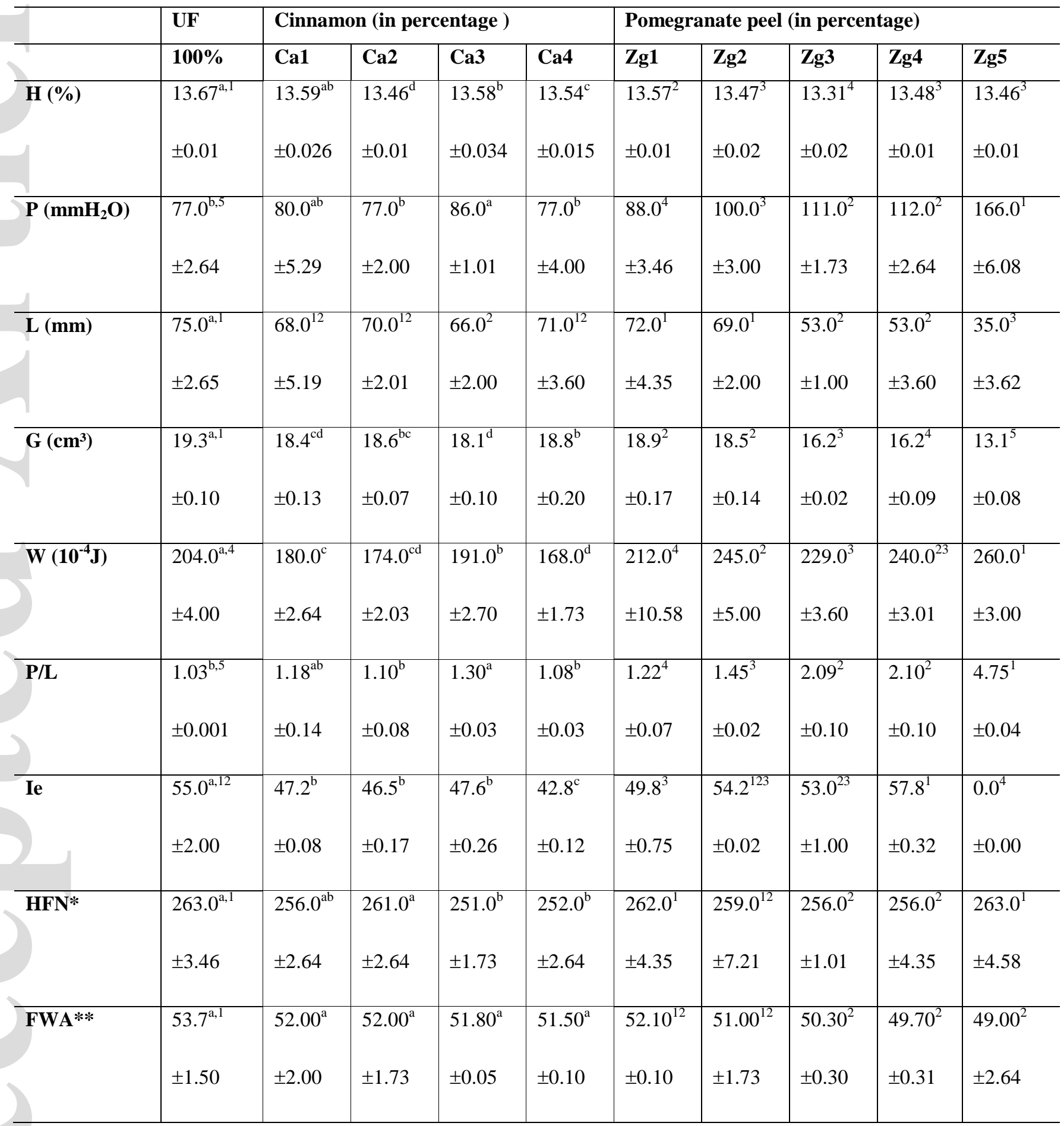

Values in the same row with different superseript letters represent significant differences between treatment for the same sample at $\mathrm{p}<0.05$ by Tukey's test $(n=3)$

Values in the same row with different superscript letters represent significant differences between enrichment with cinnamon for the same sample at $\mathrm{p}<0.05$ by Tukey's test $(\mathrm{n}=$ 3). Values in the same row with different superscript numbers represent significant 
differences between enrichment with pomegranate peel for the same sample at $p<0.05$ by Tukey's test $(\mathrm{n}=3)$

* Hagberg Falling Number

** Flour water absorption

$\mathrm{Ca} 1=0.25 \%$ cinnamon; $\mathrm{Ca} 2=0.5 \%$ cinnamon $; \mathrm{Ca} 3=0.75 \%$ cinnamon $; \mathrm{Ca} 4=1 \%$ cinnamon.

$\mathrm{Zg} 1=0.25 \%$ pomegranate $\mathrm{Zg} 2=0.5 \%$ pomegranate $\mathrm{Zg} 3=0.75 \%$ pomegranate $; \mathrm{Zg} 4=$ $1.0 \%$ pomegranate; $\mathrm{Zg} 5=1.5 \%$ pomegranate . 
Table 2. Effect of spices' incorporation on texture and chromatic proprieties of bread produced from white flour (UF) and from enriched flour, with different \% of cinnamon (Ca) or pomegranate peel $(\mathrm{Zg})$.

\begin{tabular}{|c|c|c|c|c|c|c|c|c|c|c|}
\hline & UF & Cinnar & n (in pe & centage & & Pomeg & inate pec & (in perc & tage) & \\
\hline & $100 \%$ & Ca1 & Ca2 & Ca3 & Ca4 & Zg1 & Zg2 & Zg3 & Zg4 & Zg5 \\
\hline Hardness (g) & $502^{\mathrm{e}, 4}$ & $675^{d}$ & $1006^{c}$ & $2195^{b}$ & $2364^{\mathrm{a}}$ & $1025^{3}$ & $926^{3}$ & $997^{3}$ & $1871^{2}$ & $3010^{1}$ \\
\hline & \pm 35.76 & \pm 45.96 & \pm 16.52 & \pm 15.00 & \pm 58.89 & \pm 27.50 & \pm 22.27 & \pm 10.82 & \pm 24.25 & \pm 33.80 \\
\hline Adhesiveness (J) & $245^{e, 5}$ & $295^{d}$ & $600^{c}$ & $1261^{\mathrm{a}}$ & $766^{b}$ & $492^{3}$ & $506^{3}$ & $436^{4}$ & $889^{2}$ & $1484^{1}$ \\
\hline & \pm 5.29 & \pm 7.00 & \pm 21.51 & \pm 61.50 & \pm 15.62 & \pm 11.53 & \pm 10.44 & \pm 8.66 & \pm 10.82 & \pm 13.23 \\
\hline Cohesiveness & $0.78^{\mathrm{a}, 1}$ & $0.60^{\mathrm{c}}$ & $0.67^{\mathrm{b}}$ & $0.66^{b}$ & $0.53^{\mathrm{d}}$ & $0.56^{3}$ & $0.66^{2}$ & $0.57^{3}$ & $0.59^{3}$ & $0.57^{3}$ \\
\hline & \pm 0.04 & \pm 0.02 & \pm 0.01 & \pm 0.01 & \pm 0.03 & \pm 0.04 & \pm 0.01 & \pm 0.02 & \pm 0.01 & \pm 0.01 \\
\hline Resilience & $0.45^{\mathrm{a}, 1}$ & $0.22^{d}$ & $0.34^{\mathrm{b}}$ & $0.27^{\mathrm{c}}$ & $0.21^{\mathrm{d}}$ & $0.25^{3}$ & $0.30^{2}$ & $0.24^{3}$ & $0.20^{3}$ & $0.26^{3}$ \\
\hline & \pm 0.04 & \pm 0.02 & \pm 0.02 & \pm 0.01 & \pm 0.02 & \pm 0.01 & \pm 0.04 & \pm 0.01 & \pm 0.01 & \pm 0.01 \\
\hline Springiness (m) & $0.62^{\mathrm{c}, 3}$ & $0.73^{\mathrm{b}}$ & $0.88^{\mathrm{a}}$ & $0.87^{\mathrm{a}}$ & $0.62^{\mathrm{c}}$ & $0.85^{1}$ & $0.82^{1}$ & $0.77^{2}$ & $0.81^{1}$ & $0.87^{1}$ \\
\hline & \pm 0.03 & \pm 0.03 & \pm 0.03 & \pm 0.01 & \pm 0.04 & \pm 0.02 & \pm 0.01 & \pm 0.01 & \pm 0.01 & \pm 0.02 \\
\hline Chewiness (J) & $245^{\mathrm{e}, 6}$ & $295^{\mathrm{d}}$ & $600^{c}$ & $1261^{\mathrm{a}}$ & $766^{b}$ & $492^{5}$ & $506^{4}$ & $436^{3}$ & $889^{2}$ & $1484^{1}$ \\
\hline & \pm 7.21 & \pm 16.82 & \pm 28.05 & \pm 49.56 & \pm 23.06 & \pm 5.00 & \pm 16.52 & \pm 9.85 & \pm 12.16 & \pm 15.62 \\
\hline Brown index $(b+)$ & $11.04^{\mathrm{d}, 6}$ & $11.57^{\mathrm{b}}$ & $11.39^{\mathrm{c}}$ & $11.87^{\mathrm{a}}$ & $11.65^{\mathrm{b}}$ & $11.19^{5}$ & $11.52^{4}$ & $11.89^{3}$ & $11.96^{2}$ & $12.34^{1}$ \\
\hline & \pm 0.09 & \pm 0.034 & \pm 0.036 & \pm 0.043 & \pm 0.06 & \pm 0.017 & \pm 0.036 & \pm 0.052 & \pm 0.017 & \pm 0.052 \\
\hline Yellow index $(a+)$ & $0.36^{\mathrm{c}, 1}$ & $0.54^{\mathrm{b}}$ & $0.65^{\mathrm{b}}$ & $0.84^{\mathrm{a}}$ & $0.86^{\mathrm{a}}$ & $0.37^{1}$ & $0.36^{1}$ & $0.35^{1}$ & $0.37^{1}$ & $0.31^{1}$ \\
\hline & \pm 0.05 & \pm 0.04 & \pm 0.06 & \pm 0.04 & \pm 0.017 & \pm 0.017 & \pm 0.00 & \pm 0.026 & \pm 0.02 & \pm 0.02 \\
\hline Brightness $(\mathrm{L}+)$ & $88.7^{\mathrm{a}, \mathrm{I}}$ & $88.26^{\mathrm{c}}$ & $88.53^{\mathrm{a}}$ & $87.60^{\mathrm{d}}$ & $88.37^{b}$ & $88.85^{1}$ & $88.66^{2}$ & $88.57^{2}$ & $88.19^{3}$ & $88.05^{3}$ \\
\hline & \pm 0.06 & \pm 0.036 & \pm 0.04 & \pm 0.043 & \pm 0.02 & \pm 0.02 & \pm 0.017 & \pm 0.026 & \pm 0.07 & \pm 0.043 \\
\hline
\end{tabular}

Values in the same row with different superscript letters represent significant differences between treatment for the same sample at $\mathrm{p}<0.05$ by Tukey's test $(\mathrm{n}=3)$.

Values in the same row with different superscript letters represent significant differences between enrichment with cinnamon for the same sample at $\mathrm{p}<0.05$ by Tukey's test $(\mathrm{n}=$ 
3). Values in the same row with different superscript numbers represent significant differences between enrichment with pomegranate peel for the same sample at $\mathrm{p}<0.05$ by Tukey's test $(\mathrm{n}=3)$

$\mathrm{Ca} 1=0.25 \%$ cinnamon; $\mathrm{Ca} 2=0.5 \%$ cinnamon $; \mathrm{Ca} 3=0.75 \%$ cinnamon; $\mathrm{Ca} 4=1 \%$ cinnamon.

$\mathrm{Zg} 1=0.25 \%$ pomegranate; $\mathrm{Zg} 2=0.5 \%$ pomegranate; $\mathrm{Zg} 3=0.75 \%$ pomegranate; $\mathrm{Zg} 4=$ $1.0 \%$ pomegranate; $\mathrm{Zg} 5=1.5 \%$ pomegranate. 
Table 3. Composition and nutraceutical proprieties of white flour (UF) and of enriched flour with different percentages of cinnamon and pomegranate peel.

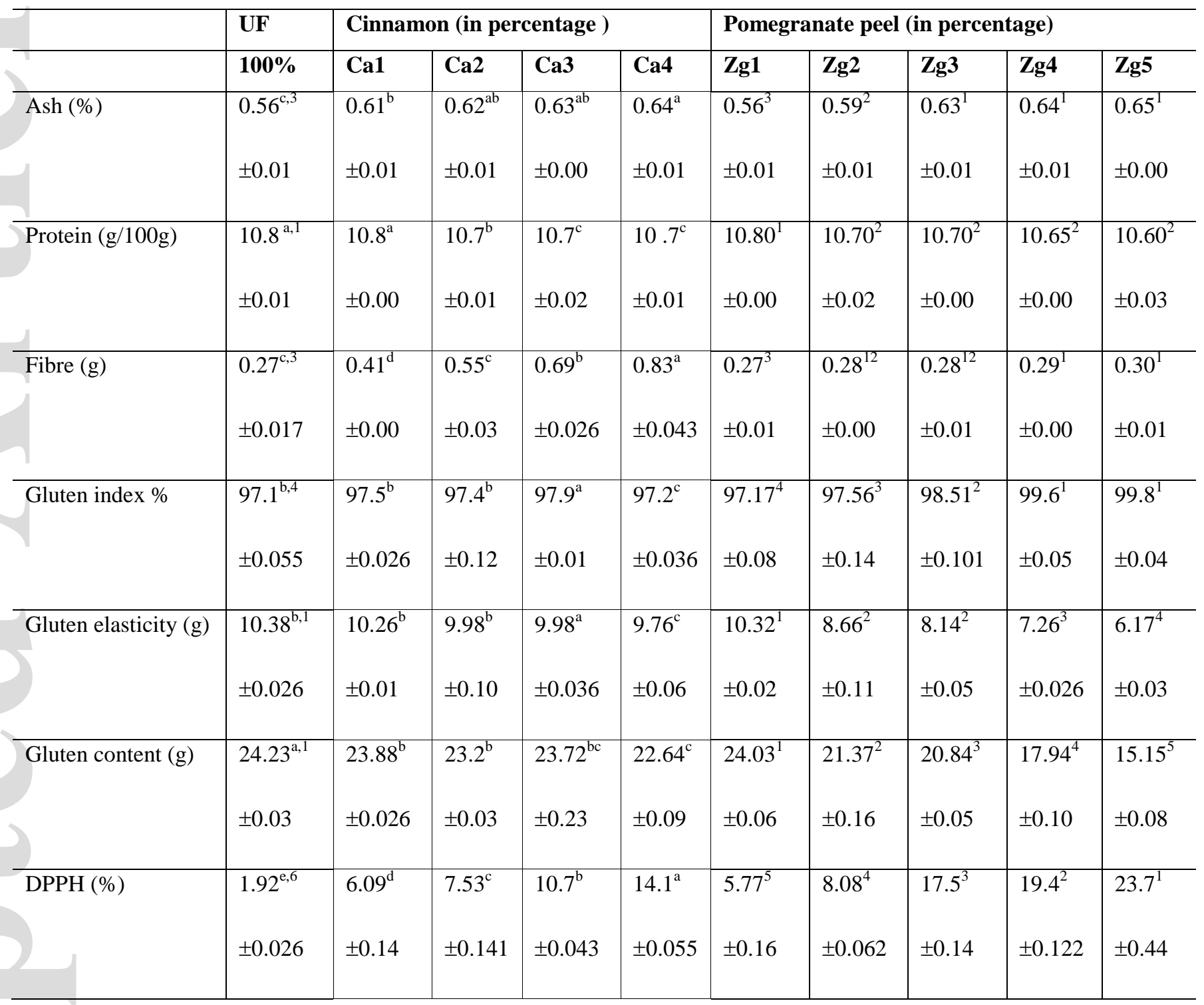

Values in the same row with different superseript letters represent significant differences between treatment for the same sample at $p<0.05$ by Tukey's test $(n=3)$.

Values in the same row with different superscript letters represent significant differences between enrichment with cinnamon for the same sample at $\mathrm{p}<0.05$ by Tukey's test $(\mathrm{n}=$ 3). Values in the same row with different superscript numbers represent significant differences between enrichment with pomegranate peel for the same sample at $p<0.05$ by Tukey's test $(\mathrm{n}=3)$

$\mathrm{Ca} 1=0.25 \%$ cinnamon $; \mathrm{Ca} 2=0.5 \%$ cinnamon $; \mathrm{Ca} 3=0.75 \%$ cinnamon $; \mathrm{Ca} 4=1 \%$ cinnamon.

$\mathrm{Zg} 1=0.25 \%$ pomegranate; $\mathrm{Zg} 2=0.5 \%$ pomegranate; $\mathrm{Zg} 3=0.75 \%$ pomegranate; $\mathrm{Zg} 4=$ 
$1.0 \%$ pomegranate; $\mathrm{Zg} 5=1.5 \%$ pomegranate .

This article is protected by copyright. All rights reserved 
Table 4. Volatile compounds in enriched bread; cinnamon: Ca100\%, and in pomegranate peel: Zg100\%; (n.d.= not detected)

\begin{tabular}{|c|c|c|c|c|c|c|c|c|c|c|c|}
\hline Volatile compounds (\%) & Ca $100 \%$ & Ca 1 & Ca 2 & Ca 3 & Ca 4 & Zg100\% & Zg 1 & $\operatorname{Zg~} 2$ & Zg 3 & $\operatorname{Zg~} 4$ & Zg5 \\
\hline Acetic acid & n.d. & n.d. & n.d. & n.d. & n.d. & 47,7 & n.d. & n.d. & n.d. & n.d. & n.d. \\
\hline Isobutyl alcohol & n.d. & 3.6 & 2.6 & 2.1 & 1.7 & n.d. & 6.3 & 3.6 & 6.0 & 6.1 & 4.6 \\
\hline 1-butanol & n.d. & 4.5 & 5.3 & 4.1 & 0.9 & 4.6 & 6.4 & 9.9 & 9.2 & 9.0 & 6.5 \\
\hline Acetoin & n.d. & 7.5 & 5.8 & 4.2 & 3.7 & n.d. & 6.2 & 6.1 & 6.7 & 8.3 & 6.1 \\
\hline Isopentyl alcohol & n.d. & 11.3 & 10.0 & 9.8 & 8.0 & 0.9 & 26.1 & 16.2 & 23.4 & 21.0 & 19.4 \\
\hline 2-methylbutanol & n.d. & 6.4 & 5.3 & 6.0 & 3.4 & n.d. & 12.1 & 8.1 & 10.9 & 9.8 & 9.1 \\
\hline 1-ethoxy-2-propanol & n.d. & 1.8 & 1.6 & 2.7 & 0.7 & n.d. & 4.2 & 2.7 & 1.6 & 2.6 & 2.1 \\
\hline Hexanal & n.d. & 1.1 & 0.9 & 1.0 & 0.5 & 2.1 & 1.4 & 2.6 & 1.5 & 1.4 & 1.8 \\
\hline dihydro-2-methyl-3(2H)-furanone & n.d. & 0.9 & 0.9 & 0.8 & 0.2 & n.d. & n.d. & n.d. & n.d. & 0.8 & 0.9 \\
\hline Methylpyrazine & n.d. & 1.4 & 1.3 & 1.1 & 0.3 & n.d. & 0.9 & 1.8 & 1.0 & 1.3 & 1.4 \\
\hline Furfural & n.d. & 8.7 & 10.4 & 9.9 & 2.0 & 0.8 & 5.3 & 6.4 & 3.9 & 5.7 & 4.6 \\
\hline Furfuryl alcohol & n.d. & 6.1 & 8.9 & 4.8 & 2.1 & n.d. & 4.6 & 7.3 & 5.9 & 8.0 & 6.8 \\
\hline Heptanal & n.d. & n.d. & n.d. & n.d. & n.d. & n.d. & 2.2 & 2.5 & 1.8 & 1.2 & 0.6 \\
\hline 2,6-dimethylpyrazine & n.d. & 0.9 & 1.0 & 0.9 & 0.3 & n.d. & 0.8 & 1.3 & 0.8 & 0.9 & 0.7 \\
\hline 2-ethylpyrazine & n.d. & 1.3 & 1.6 & 1.3 & 0.4 & n.d. & n.d. & 1.5 & 1.4 & 1.5 & 1.1 \\
\hline 2,3-dimethylpyrazine & n.d. & 1.0 & 1.0 & 0.9 & 0.2 & n.d. & 0.3 & 1.1 & 1.2 & 1.0 & 0.9 \\
\hline Benzaldehyde & 0,4 & 0.3 & 0.4 & 0.5 & 0.3 & 1.5 & 0.7 & 1.1 & 0.5 & 0.4 & 0.4 \\
\hline 5-methylfurfural & n.d. & 2.1 & 2.5 & 1.4 & 0.5 & n.d. & 1.3 & 1.7 & 1.0 & 1.4 & 1.2 \\
\hline 2-pentyl furan & n.d. & 0.5 & 0.5 & 0.3 & n.d. & n.d. & 0.9 & 0.6 & 0.6 & 0.7 & 0.8 \\
\hline Butyl butyrate & n.d. & 0.8 & 0.6 & 0.6 & 0.5 & 1.4 & 1.6 & 1.7 & 1.2 & 1.1 & 0.9 \\
\hline 3-ethyl-1-hexanol & n.d. & 1.2 & 0.7 & 0.7 & 0.5 & 1.4 & 1.4 & 1.6 & 2.4 & 1.5 & 1.4 \\
\hline Limonene & 0,3 & 8.2 & 7.4 & 7.1 & 37.1 & 17.9 & 8.6 & 8.4 & 7.6 & 7.3 & 18.2 \\
\hline 1,8-cineole & 0,3 & 1.2 & 0.8 & 0.8 & 1.5 & n.d. & 1.2 & 1.2 & 1.5 & 1.7 & 1.9 \\
\hline
\end{tabular}

This article is protected by copyright. All rights reserved 


\begin{tabular}{|c|c|c|c|c|c|c|c|c|c|c|c|}
\hline Linalool & 8.5 & 1.4 & 1.5 & 1.9 & 2.0 & 3.1 & 1.2 & 1.8 & 1.5 & 1.1 & 1.7 \\
\hline Nonanal & n.d. & 1.1 & 0.7 & 0.8 & 0.5 & 3.0 & 1.4 & 5.6 & 2.3 & 1.0 & 3.0 \\
\hline Hydrocinnamyl alcohol & n.d. & 2.3 & 2.7 & 3.5 & 3.5 & n.d. & n.d. & n.d. & n.d. & n.d. & n.d. \\
\hline Carvone & 17.5 & 7.1 & 7.3 & 9.4 & 8.1 & n.d. & n.d. & n.d. & n.d. & n.d. & n.d. \\
\hline (E)-cinnamaldehyde & 30.5 & 3.3 & 1.2 & 2.0 & 1.7 & n.d. & n.d. & n.d. & n.d. & n.d. & n.d. \\
\hline Cyclosativene & 1.4 & n.d. & n.d. & n.d. & 0.3 & n.d. & n.d. & n.d. & n.d. & n.d. & n.d. \\
\hline$\alpha$-copaene & 15.6 & 3.5 & 5.1 & 7.3 & 5.0 & n.d. & n.d. & n.d. & n.d. & n.d. & n.d. \\
\hline Sativene & 1.1 & n.d. & n.d. & n.d. & n.d. & n.d. & n.d. & n.d. & n.d. & n.d. & n.d. \\
\hline$\beta$-caryophyllene & 2.1 & 0.4 & 0.6 & 0.8 & 0.7 & n.d. & n.d. & n.d. & n.d. & n.d. & n.d. \\
\hline$\gamma$-muurolene & 1.5 & 0.4 & 0.5 & 0.7 & 0.6 & n.d. & n.d. & n.d. & n.d. & n.d. & n.d. \\
\hline$\alpha$-muurolene & 5.3 & 1.4 & 1.9 & 2.7 & 2.7 & n.d. & n.d. & n.d. & n.d. & n.d. & n.d. \\
\hline$\delta$-cadinene & 6.5 & 1.9 & 2.5 & 3.8 & 3.3 & n.d. & n.d. & n.d. & n.d. & n.d. & n.d. \\
\hline
\end{tabular}

This article is protected by copyright. All rights reserved 
Table 5. Statistical analysis of hedonic study of bread produced from white flour (UF) and from enriched flour with different $\%$ of cinnamon $(\mathrm{Ca})$ or pomegranate peel $(\mathrm{Zg})$

\section{Factors}

\begin{tabular}{l|ccc} 
& Gender & Age & Interaction \\
\cline { 2 - 4 } & & Taste \\
\hline Formulations & & & \\
\hline Zg & $* *$ & $* * *$ & $* *$ \\
Ca & $* *$ & N.s & $* * *$ \\
UF & N.s & $* *$ & $* * *$
\end{tabular}

\begin{tabular}{l|ccc}
\hline \multicolumn{1}{l}{} & & Texture & \\
\hline Zg & N.s & $* *$ & $* *$ \\
\hline Ca & $* *$ & $* * *$ & N.s \\
\hline UF & $* *$ & N.s & $* * *$ \\
\hline & & Aroma & \\
\hline Zg & N.s & N.s & N.s \\
Ca & N.s & $* * *$ & N.s \\
UF & $* *$ & N.s & N.s \\
\hline & & Overall liking & \\
\hline Zg & N.s & $* * *$ & N.s \\
Ca & $* *$ & N.s & $* *$ \\
UF & $* *$ & $* *$ & N.s \\
\hline
\end{tabular}

$* * * \mathrm{P}<0.001 ; * * \mathrm{P}<0.01 ;$ N.s: Not significant 

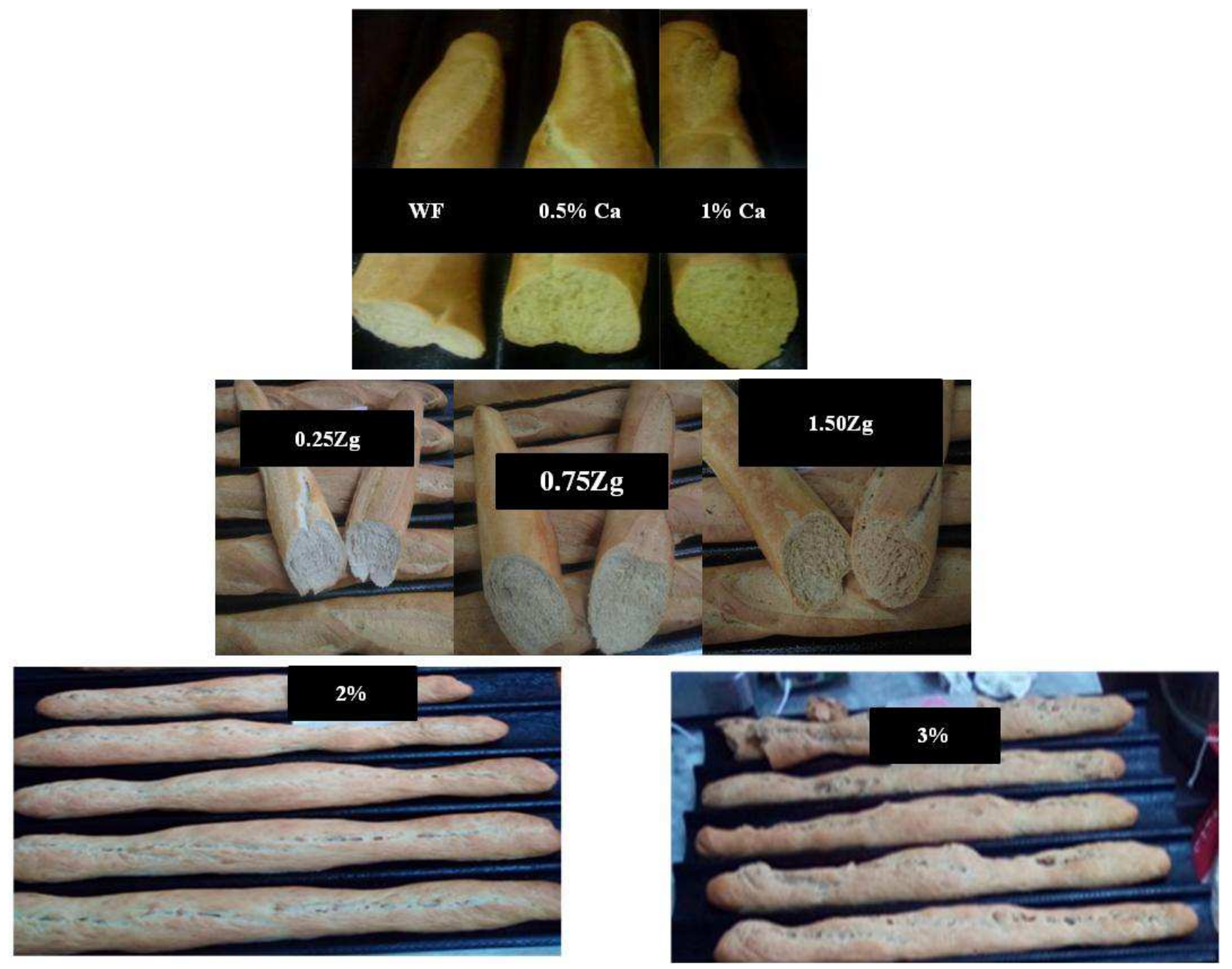

Figure 1.

Appearance of bread's texture obtained from white flour's control (WF) and from different enriching formulations $(\mathrm{Ca}=\mathrm{cinnamon}$; $\mathrm{Zg}=$ pomegranate), in decreasing order of textural features, from top to bottom.

This article is protected by copyright. All rights reserved 


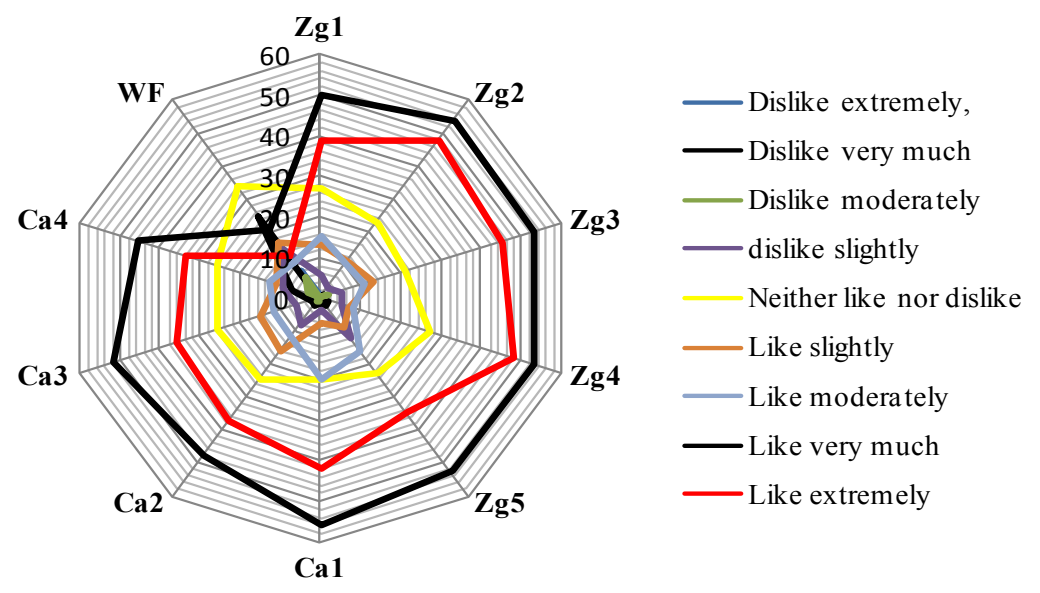

A. Overall liking

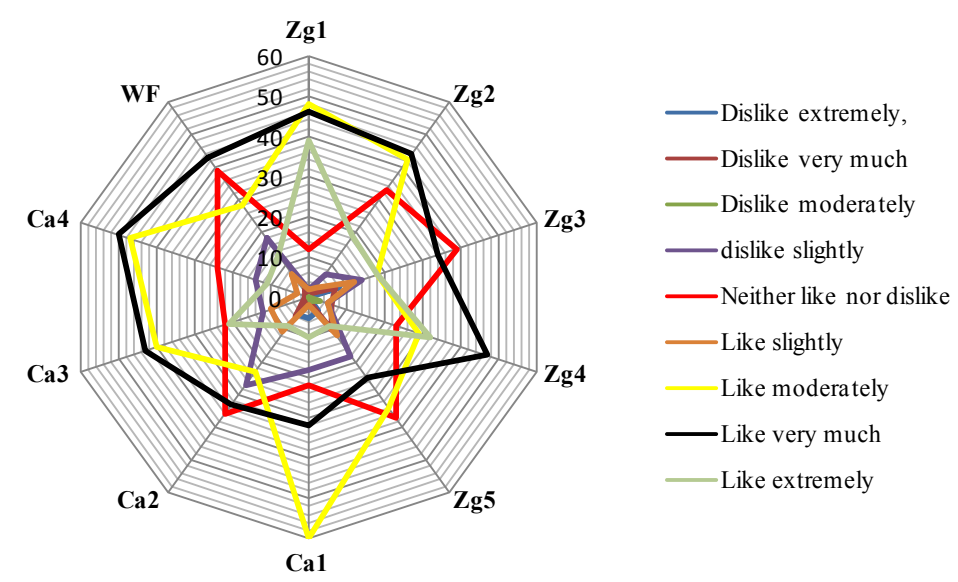

C. Texture

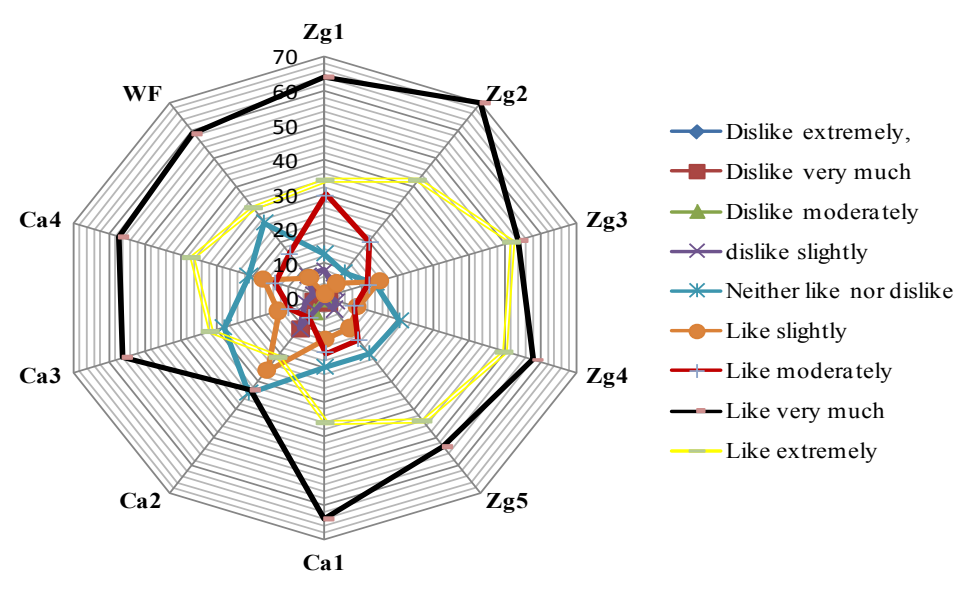

B. Taste

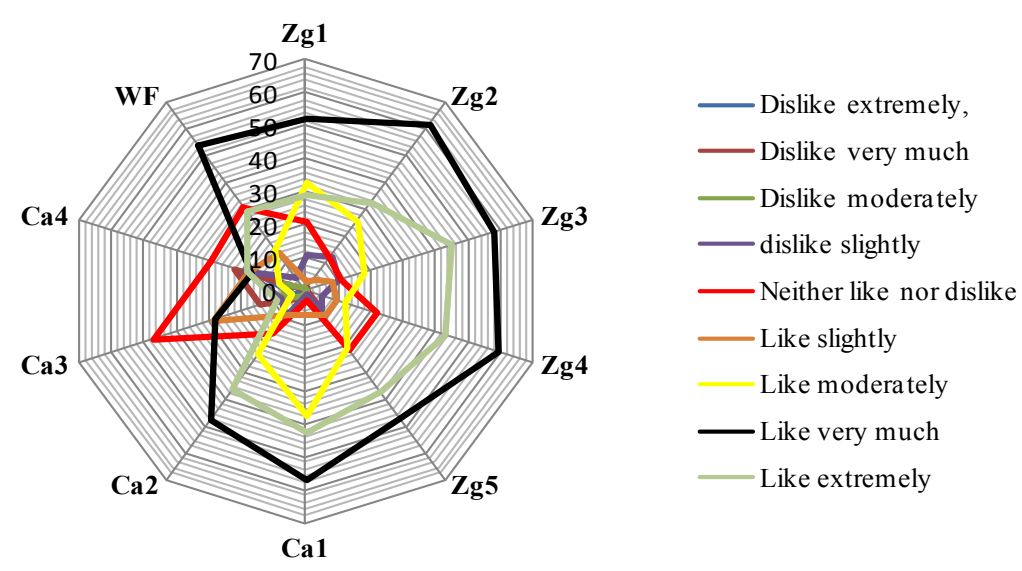

D. Odour

This article is protected by copyright. All rights reserved 
Figure 2

Sensory evaluation of bread formulations, prepared with white wheat flour enriched with different percentages of cinnamon or pomegranate peel powder. Diagrams show obtained ratings for WF (control) and enriched bread with cinnamon (Ca1 to $\mathrm{Ca} 4)$ or pomegranate peel powder ( $\mathrm{Zg} 1$ to Zg5) in respect to A. Overall liking, B. Taste, C. Texture, and D. Odour. 